\title{
Statistics for Policy and Planning in Canadian Higher Education: An Ontario Perspective
}

\author{
MARIO CREET * and BERNARD TROTTER **
}

\begin{abstract}
Systems of information about higher education in Canada are in a mess. Substantively they are being developed on the basis of doubtful assumptions and confused purposes. Data for administrative and financial control are being confused with data needed for policy and planning purposes. Data systems are designed without due regard to practicality cost and need. A dubious passion for all purpose systems obscures the necessary role of special data sampling projects and special analyses in throwing light upon choices for the future. Planners and policy makers continue to act as if projection methods appropriate for the fifties are still sufficient for the future. Procedures for the development of information systems are being left to people who tend to be preoccupied with day-to-day and technical concerns, unrestrained by university and government policy makers who prefer. to ignore or refuse to see that the gathering and presenting of statistical information acts directly on the policy and planning process. The demonstrated lack of interest by most senior leaders in government and in the universities in the assumptions, methods and procedures involved in collecting and analyzing information is illustrated by the failure of both universities and governments to develop separate or joint capacities for continuing analysis on a national basis of what is happening and why. Substantial work done at the provincial and regional level is not brought together for examination from a national perspective. If the universities do not themselves take corrective action, this failure will progressively reinforce the "provincialization" of universities so much deplored by academic leaders as being antithetical to the basic nature of authentic universities. The data needs associated with control should become the responsibility of provincial jurisdictions while the resources of Statistics Canada and the energy of AUCC should be oriented to policy information relating to global, national and interprovincial questions.
\end{abstract}

* Senior Research Officer, Office of Academic Planning, Queen's University.

** Head, Office of Academic Planning, Queen's University. 


\section{RÉSUMÉ}

Les systèmes d'information en matière de l'enseignement supérieur au Canada sont actuellement à l'envers. Plus précisément, leur développement se base sur des hypothèses douteuses et des objectifs confus. Les données de contrôle administratif et économique se mélent avec celles requises pour les fins de la formulation de la politique et de la planification. Les systèmes de données se proposent sans égards suffisants au caractère pratique, au coût et au besoin. Une passion douteuse, pour un système à tous usages, obscurcit le rôle nécessaire des projets spéciaux d'échantillons de données ainsi que des analyses spéciales pour jeter de la lumière sur des choix pour l'avenir. Les planificateurs et les auteurs de la politique continuent à réagir comme si les méthodes de prévisions appropriées aux années cinquante sont toujours suffisantes pour l'avenir. Les modes de procédure pour le développement des systèmes d'information se placent dans les mains de ceux qui ont tendance à se préoccuper des soucis techniques et au jour le jour, aucunement restreints par les auteurs de la politique universitaire ou gouvernementale qui préfèrent ne pas vouloir reconnaitre ou qui préfèrent refuser de voir que la cueillette et la présentation de données statistiques agissent directement sur la formulation de la politique et sur la planification. Le manque d'intérêt manifesté par les chefs supérieurs, qu gouvernement ainsi que dans l'université, à l'égard des présomptions, des méthodes et des modes de procédure dont il est question pour la cueillette et l'analyse des informations s'explique par l'échec des universités et des gouvernements de développer séparément ou conjointement les moyens d'analyse continue, à l'échelle nationale, de ce qui se passe et pourquoi. Des travaux importants effectués aux niveaux provincial et régional ne se coordonnent pas pour permettre un examen dans une perspective nationale. Si les universités ellesmêmes ne prennent pas des démarches correctives, cet échec ira en renforçant la "provincialisation" des universités, tant déplorée par les dirigeants des institutions académiques, vue comme l'antithèse de la nature même des universités authentiques. Les besoins en données coordonnées sous des contrôles devraient se faire la responsabilité des juridictions provinciales tandis que les ressources de Statistiques Canada et les efforts de l'AUCC devraient s'orienter vers toute question d'intérêt mondial, national et interprovincial.

\section{From the 1960 s to the $1970 \mathrm{~s}$}

Historically, the Dominion Bureau of Statistics (now Statistics Canada) collected and published statistics on enrolment and educational finance. These provided a basis for planning until provincial governments began to establish more and more complex information systems with the expansion of universities in the sixties. As funding became more directly tied to enrolments, provincial data requirements developed greater emphasis on financial control. The attempt is now being made in Ontario, at least, to combine the Provincial and Statistics Canada data collection and processing in a single all-purpose system. We will examine the implications of this development later. But the collection and presentation of statistical material is of little assistance in policy and planning without continuing critical examination of what the statistics mean and, more importantly, of the assumptions upon which various interpretations are based. Such regular interpretation was provided 
for a period of eleven years by E.F. Sheffield (with the Dominion Bureau of Statistics, 1954-58, with the Association of Universities and Colleges of Canada, 1958-66) in a series of enrolment projections for the country as a whole beginning in 1955 .

In the decade which followed, universities and governments, with Sheffield's help, came first to see the inevitability of major university expansion, to recognize the dimensions of the task to be undertaken, and to plan for its accomplishment. Since 1966, the year of Sheffield's last projection, no single agency has assumed responsibility for continuing his work on a regular basis. His work, as we have already indicated, consisted of accumulating aggregate data on enrolments, putting them in national and international contexts and interpreting the results for policy makers. Since 1966 we have had, instead, a division of labour into data accumulation and interpretation for policy, the first being published in annual bulletins by Statistics Canada* and the second being treated in occasional studies or papers presented to limited audiences.** Other projections have been prepared under various auspices on a province by province or regional basis. For Ontario, Zsigmond and his associates in Statistics Canada have recently published the most complex analysis yet attempted.*** Altogether, there has been ambiguity in the performance of these roles brought about by the division of labour. Data bulletins often contain extrapolations which can be mistaken for planning projections, but such extrapolations tend to be mechanical and to lack interpretive insights. The more consciously analytical studies tend to be ambivalent about whether they are offering policy advice and to whom they are offering it. Our prime concern is to examine the nature of the change in information and not its causes, but a brief reference to them here would be in accord with our concluding comments. Together with the many fold increase in public expenditure on higher education, the shift from federal to provincial concern with universities has helped to accentuate "accountability" to provincial jurisdictions and to squeeze out national or international considerations. The national role of the AUCC and of Statistics Canada in higher education (and of the universities themselves) has, therefore, become problematic, as noted in Planning for Planning (Trotter and Carrothers, reference 7) and in the OECD Review for Canada (reference 5).

\section{Some Key Notions}

In order to illustrate the kind of information which assists policy and planning judgements it will be helpful to compare and contrast the Sheffield projections of the sixties (reference 6) with Zsigmond's most recent work (reference 11). The structure of the information is simple and the same in both cases: it consists of two parts and a relationship between them. One part is the demographic base and its likely shape in the future; the other part is full-time enrolments broken down by various categories. The relationship is the proportion of appropriate segments of the population enrolled full-time in higher education. As the latter figure is difficult to obtain accurately, a proxy has been widely used in its place, i.e. the participation rate, or full-time enrolment as a percentage of a particular age group. By convention, the age group has been 18 to 24 for total full-time

\footnotetext{
* e.g. catalogue 81-220, Advance Statistics of Education.

** Zsigmond: Economic Council of Canada, Staff Studies Nos. 20 and 25; also references \# 10 and 11. Wisenthal: AUCC, 1973; reference \# 9.

*** Reference \# 11 .
} 
enrolment, and 18 to 21 and 22 to 24 for the undergraduate and graduate sectors respectively. Another important division has been the presentation of these sectors for each gender, because men and women have participated unequally in higher education and their participation has changed at different rates.

What makes these reports useful and therefore influential to policy makers? First is their simplicity of structure and their high level of aggregation which together transform data into information; such transformation is essential if the statistics are to be invested with meaning. If such selection and transformation are not carried out, the pile of facts will be about as useful to planners and policy makers as the Guinness Book of Records. Second is the way in which information is related to policy concerns. For example, we note some assumptions and values which tend to be associated with the participation rate: first, that $18-24$ functions as a social norm for the age group appropriate to higher education and that, while the actual age distribution of students should be made known, it will impinge on planning and policy making only if it gives strong signs of departing from this norm; second, that equality of the participation of each gender is taken for granted as a goal and that information on the actual outcomes exerts a continual pressure toward equalization; third, that myriad social, political and economic factors are intermingled in bringing about an overall rate of participation and that a given level of participation, whatever it happens to be, can only be judged in context. In other words, the participation rate will be seen as too high or too low depending on what has happened in the recent past and is expected of the near future, especially when compared with other similar societies.

\section{Why did it work in the 1960 s?}

All these features of the participation rate were explicitly discussed in the Sheffield projections, notably in 1963 and 1966. The American experience was frankly adopted as the model for comparison. In Sheffield's view Canada was lagging the model by about 15 years. Most important, from our point of view, was Sheffield's observation that social objectives seemed to override the purely economic in policies for access to Canadian universities. As he stated it: "Our society talks and acts as if individuals should be given opportunity commensurate with their talents." He then argued that rather than "attempt to measure and take account of the host of factors (economic, social, organizational, etc.) which influence young people to attend, or not to attend university" it is more reliable to examine trends which are "the resultants of such hosts of factors. Any attempt to isolate and measure individual factors is likely to prove as difficult as the forecasting of manpower needs." After further discussion he concluded: "In sum, we proceed with some assurance that the "simple" procedures we have been using work - imperfectly, it is true, but well enough to have proven useful." (Reference 6:1966 pp 7,9). And work they did, until the early 1970's when Canadian society continued to talk, but given substantially higher levels of expectation, no longer acted "as if individuals should be given opportunity commensurate with their talents." The notion of opportunity had by then expanded to include not only access to enough places in higher education but also incentives to continue with prior education and the entitlement to career benefits from higher education through appropriate job opportunities. By the end of the sixties a gap 
was already evident between these rising expectations and what the system could realistically provide. Extrapolating the trend of participation rates, as Sheffield had done with good judgement, would no longer suffice. However, neither Miles Wisenthal, who discussed the problem at the 1973 annual AUCC conference (reference 9), nor Zoltan Zsigmond at the 1975 Conference of Learned Societies (reference 10), were prepared to abandon the simple structure of demographic profile and participation rate. Wisenthal was persuasive in his view that participation would continue to rise, though perhaps more slowly, after the temporary halt of 1972 . Zsigmond drew a compelling picture of enrolments beginning to fluctuate in tune with the demographic "roller-coaster". Most recently, Zsigmond and his associates have presented a more complex analysis (though confined to Ontario) than any done previously (reference 11). They acknowledge, as did Wisenthal, the effects of manpower demand, but the basic structure of projected enrolments remains a combination of demographic data and estimates of participation. The difficulty with such a focus is that while Sheffield could confidently infer a social policy moving clearly in an expansionist direction, and could assume behavioural patterns in which qualified young people would more or less unanimously exploit the opportunities offered, we now find ourselves in a climate of almost total uncertainty about government policies, public expectations, and the choices which potential students are likely to make.

\section{What is missing in the 1970s?}

In the circumstances, projections based on the Sheffield model can be only the beginning and not the end of a planning and policy making process. The "roller-coaster", once understood as an unacceptable future for institutions in which society has invested tremendous physical and human resources and which will be required on something like their present scale in the longer run, suggests the need for other information, the analysis of which will assist the formulation of policies directed towards flattening out the more breath-taking slopes of the roller-coaster. Two special studies mentioned below illustrate the kinds of information and analysis increasingly required if sensible and practical policy paths are to be found through the maze of current complexities. Both studies illustrate the futility of designing routine statistical collections so as to anticipate special needs. Apart from all else, the expense of routine collection of for example, student financial and attitudinal data would be prohibitive. Since routine data on students is collected at registration - already a time-consuming trauma for students and officials alike - more than mild consumer resistance could also be expected.

Moreover, on some issues information is needed which cannot and could not be obtained through routine collection methods. Demand for Part-Time Learning in Ontario by Ignacy Waniewicz (reference 8 )* provides a prime example of such information. The author, Research Director of the Ontario Educational Communications Authority, identified a large gap in the information on the potential demand for part-time education and conducted a survey of the "market" in Ontario. Among other facts, he found that there was some potential new demand for part-time degree credit work, but that demand seemed to be much less than had been generally believed to be the case. He thus corrected the perception of The Commission on Post-Secondary Education in Ontario four years earlier. That Commission undertook almost a score of special studies in pursuit of infor-

\footnotetext{
* Reviewed in The Canadian Journal of Higher Education, Volume VII, Number 3.
} 
mation pertinent to policy issues under study. On what turned out to be the major thrust of its report, however, it allowed itself to be misled by the available routine data on parttime enrolments, by the advocacy of special interest groups and by its own predilections. It, therefore, sought no evidence which might have cast doubt on the vision of an entire society given up to learning or on the credibility of recommendations that the Government of Ontario become midwife to the new society. Waniewicz's study, had it been available to the Commission, might have served to moderate and focus these ambitions and thereby render them perhaps more effective than in the event they were.

The point to note from this example is that in a situation of rapid flux, annual data collections will almost always provide inadequate bases for analysis of complex change in which the factors at play are themselves problematic. This point needs to be stressed because it contradicts the belief that an annual collection, if it is sufficiently comprehensive, can monitor situations in rapid flux. No matter how comprehensive, routine collections must be based on definitions and assumptions drawn from the past, i.e. on things which appear from experience to be self-evident. Adequate planning for the future must depend heavily upon objective study designed to test the continued validity of even the most "self-evident" of such assumptions.

While the Waniewicz study was too late (through no fault of the author) to affect COPSEO's recommendations, it has nevertheless turned out to be directly relevant to the current policy response to the "roller-coaster." Off-the-cuff judgements had assumed that part-time enrolments could be expanded in the eighties to offset the projected declines in full-time enrolment. The data collected by Waniewicz cast decisive doubt on this already tenuous possibility.

The policy response to the "roller-coaster" must also rely heavily on diagnosis of the impact of sources of finance on student participation. Important evidence is provided in the second of the recently published special studies to which we referred above. Some Characteristics of Post-Secondary Students in Canada by B. Ahamad, D. Zussman, and A. Bowen (reference 1 reviewed in Volume VII number 2 of Canadian Journal of Higher Education) presents the results of a survey carried out in 1975 under the aegis of the Secretary of State and is largely descriptive. Yet a finding that students depend more heavily on summer earnings than any other single source of financial support and that job opportunities for students are therefore a critical element in accessibility has yet to be seriously reflected in policy discussions of student aid patterns. The Ahamad report does not appear to have been noticed by policy makers in spite of its obvious connection with university access. For example, the "Report of the Interim Committee on Student Financial Assistance" (in Ontario), co-chaired by S. Dupré and N. Sisco (reference 3) recommends substitution of a new program of grants and loans to consolidate and replace the several schemes which have been in operation for varying lengths of time, some since the mid-1960's. But this Report appears to have ignored all information pertinent to the performance of existing student aid programs and to the financial behaviour exhibited by students. Although the study by Ahamad et al was not published until the Interim Committee was almost ready to report, it could have been made available in draft form had the Committee wanted information.

By contrast the demographic "roller-coaster" publicized by Zsigmond has received almost universal attention from policy makers.* There has been a growing reaction, 
however, to the basic assumption of constant, or slowly changing, participation rates which underlies the "roller-coaster" projection. Planners and policy makers have begun to realize that supply need not always follow demand for higher education, and that, in the crucial decade ahead, it could well be that supply would not be directly tied to demand, whether it be for places or for manpower from the public and private sector of the economy. In other words matters might be arranged so that the capacity of institutions will be the dominant, if not determining, influence on enrolments in universities. If so, the projections for the next decade would be based on "capacity" and would probably imply a global steady state, though not necessarily so within each institution. Some caution is necessary here in interpreting "capacity": it is a complex notion involving much more than the physical facilities of an institution and is somewhat elastic depending on the perceived demand (in the sense both of pressure from admission and specialized manpower requirement). So what is emphatically not needed is a massive new compilation of data on the physical facilities on each campus; rather, there is a distinct need for central coordination and analysis of information on capacity, the source of which can only be a local determination at each institution of what enrolments it can serve, given one or other set of assumptions.

Having illustrated the necessity of special collections and analysis of information pertinent to particular aspects of the policy dilemma, we turn to the examination of routine data collections.

\section{Prevalent Assumptions}

Unfortunately, the notion of the all-purpose collection persists in the face of substantial evidence that it is wasteful, of poor quality, and potentially distorting in its effects. The first major sign of the all-purpose syndrome was the establishment by Statistics Canada with the encouragement of Provincial authorities, of the University Student Information System (USIS) in 1971. The premise of the system was that a sophisticated annual collection of data would permit the monitoring of many kinds of change. Were there changes taking place in the age distribution of students, the sequence from high school, the rates of retention and graduation, the number of part-time people, etc.? In a few years, the information from USIS and similar collections would answer these questions for planners and policy makers on a continuing basis. However, in Appendix C of the Ontario study (reference 11, pages 229-233) we are told that such data are of medium to poor quality or simply not available. Logically, this is exactly what one would expect, because the very fact of rapid change should render unworkable some of the fine-tuned definitions which are necessary to a very detailed computer-based system.

A more appropriate strategy to meet planning and policy needs would have been to maintain a system designed for a high level of aggregation and based on broad definitions, supplemented by special studies based on sampling techniques. Instead, the diagnosis has been that the institutions which provide the data have fallen down on the job, and the proposed cure (for Ontario at least) is that the institutions must be made to treat all items

* For example, see Introduction, Second and Third A nnual Reports, Ontario Council on University Affairs, 1976 and 1977. See also responses of Council of Ontario Universities and of individual universities to these intorductions in briefs to OCUA. 
of data as if they were needed for financial control.* In other words, the assumption is that there should be an all-encompassing pool of high precision items from which facts can be fished to serve all conceivable purposes. This collection of conceits might be dubbed the "all-purpose flour" system.

What's in the bag of "all-purpose flour"? A set of assumptions which goes something like this:

a. one piece of information is like another, like grains of flour.

b. a collection of pieces is as structureless as flour on the macroscopic scale.

c. the finer and the more even the grind the better.

d. with suitable additives, one can make bread, sauce or batter to suit all known purposes.

e. any new purposes can be met by throwing in some new additives.

The "all-purpose flour" analogy doesn't work, for our minds are far more discriminating than our stomachs. Have we invented some non-existent "flour people" for the sake of a talking point? The USIS collection initiated by Statistics Canada early in this decade incorporated some of these assumptions. The Ministry of Colleges and Universities in Ontario is now pushing hard to go all the way to a single, multi-purpose system. Whether this effort is successful or not, there can be no doubt of the strong thrust in this direction evident in the actions of provincial ministries concerned with higher education elsewhere in Canada. In other words, information system designers have as their goal the accumulation of data, updated recurrently (often more than once a year), which will answer any question and will enable users both to carry out routine administrative functions and to monitor social and institutional changes. Their basic assumptions are that all pieces of information have equal value and should be procured for all individuals in the system, and the more data on everybody the better. Their goal is to accumulate all kinds of information in the smallest possible units so that they can be combined to suit any purpose.

\section{Alternative Criteria}

By contrast, we would suggest that the ways of meeting needs or anticipated demands for information be assessed on three criteria related to intended meaning and estimated cost: structure, frequency and accuracy.

i. structure: the terms in which we understand and deal with the situation in question; the example has been given of the demographic base, the university population and their mutual relation as the prime way of examining trends in higher education. The recent action taken in Ontario by the Ministry of Colleges and Universities of obliterating the distinction between full-time and part-time status has led to a loss of meaning.**

* This is a specific reference to a proposal, from the Ministry of Colleges and Universities of Ontario to merge the USIS file and the Ministry's own financial counts.

** To be specific, the count is based on course loads; e.g. a student registered for four courses in a program whose norm is five counts as 0.8 of a fiscal full-time equivalent, similarly course loads of five and six count as 1.0 and 1.2 respectively. And part-time students are counted in the same fashion. Hence a f.f.t.e. of 1.8 might stand for two full-time students or one full-time and one part-time; again 2.4 f.f.t.e. might be several part-time students or two full-time students or two full-time and a part-time student. The loss of meaning is obvious. When the same technique is applied to programs which are not as simply constructed as a B.A., i.e. in most professional programs, defining the norm is itself a problem. In these cases the method can become very complex. 
This action was taken on the grounds that such status could not be defined with unchanging exactness and, hence, that reduction to the unit of activity, the course, would lead to a simplification of meaning, to lower cost for collection and to more precise financial control. The assertion has been proved wrong on all counts, but we are now stuck with this problem in Ontario and it will soon affect Statistics Canada as well. Evidence of this can be found in the brief presented by the Council of Ontario Universities (COU) to the Ontario Council on University Affairs (OCUA) (reference 2). Although the main concern of the brief is with levels of funding, the uncertainty brought about by the new counting scheme is a central feature.* Nevertheless, the OCUA has persisted in its position that counting is an administrative not a policy matter and has declined to offer advice.

ii. frequency: which items need to go into a routine and recurrent collection; which situations should be examined only occasionally? Apart from the operational requirements set by financing arrangements (i.e. those items required for control of institutions by government agencies), relatively few items can be justified for information on a recurrent basis; in the case of students, these are enrolments and graduations by program, status, level, age, gender and citizenship. Many other trends, which are usually sought from a recurrent collection, need only occasional monitoring because they change much more slowly than the first sort; e.g. continuing education, representation from social class and language groups, employment fits, inter-provincial mobility, etc. The price of including this second sort in a recurrent collection is a reduction of quality in information of the first sort (as well as greatly increased costs of collection). The loss in quality occurs because there is no gradation for acceptable accuracy.

iii. accuracy: this involves both the reliability of items in a record and the completeness . of the record, and overlaps closely with frequency. The suggestion here is that those items which are necessary for recurrent collection should be given priority, so that both the input data and those computed from them are reliable at specified levels. On the other hand, if items like mother tongue or place of residence are also collected annually and with the same intolerance of error, data collections become cumbersome to maintain and operate.

\section{Another Path}

The positive requirements of the studies we have noticed are not being met by present-day information collections. Although our illustrations have been drawn from information about students, and particularly from Ontario because of its familiarity for us, we may say that the tendencies which we have dubbed "all-purpose flour" generally prevail in all

* In the middel of its brief, Foundation for an Uncertain Future: the Operating Base, the COU Committee takes up the question of what the enrolment in Ontario Universities in 1976-1977 actually was. The Committee's answer is that there could have been an increase of up to $2 \%$ over the enrolment of the previous year, but this was being obscured by the changes brought about by the method of counting which seems to have introduced an uncertainty of at least $1 \%$. If one bears in mind that the funding formula in Ontario is built around enrolment and that the question is being addressed some months after the official count date, neither the importance of the question nor the anxiety aroused by its answer need be belaboured. 
sectors of information (excepting perhaps the financial) on higher education in Canada. This has happened because those who are involved in designing and maintaining these systems are exclusively oriented towards the day-to-day tasks of either information system management or institutional (including the province-wide) administration. To the extent that they have been sensitive to the concerns of planners and policy makers, system managers and administrators have sought to satisfy the concerns by making the recurrent collections of information more comprehensive, by adding on more bits as if they were all alike and needed to the same degree.

An information system must have formulators to design it and make it work and users to justify it. The procedural assumption now generally operative results in the administrative function being central to any change or development of the system, so that technical and administrative requirements override all other considerations and the needs of planners and policy makers are met only as a spin-off from the main thrust. In short, it is assumed that setting up a system is an administrative matter designed by administrators for administrators. Systems set up to provide administrative control work differently from and overlap only occasionally with those which monitor and thus provide a basis for planning and persuasion. The administrative function needs detailed and precise information for control, in contrast to the requirements we have described for policy making. Each should be served by systems tailored to its needs. At the same time, this distinction does not mean that there should be two completely independent systems with no cross-over between them. That would be equally bad because the management and policy making functions do overlap. Statistics tell planners and policy makers about the way things have gone and how they might go if certain kinds of decisions are taken. They assist but do not replace informed judgement. But it is essential that statistical data be pertinent to the questions upon which judgement must be rendered. Thus, if policy and planning issues are not confronted in the formulation of systems the policy maker will be more in the dark than he should or needs to be. If the only information available is that for control, management assumptions will colour the context and presentation of statistics to policy makers and planners.

A scheme better designed to meet these requirements would be segmented to the extent that there would be a common data core of mutual interest to the different groups, and this core would be superimposed on the routine requirements of the administrative function and be supplemented by the continuing and occasional collections appropriate to the policy and planning function. Here formulation is shared by planners and policy makers who can not only ensure that their needs are taken into account but also that control systems do not have the potential to distort or abort activities essential to planning and policy purposes. But it must be said that this is not meant to imply a single all-purpose system. On the contrary, it requires that such systems be designed only when each of the purposes to be served is compatible with efficiency, accuracy and cost effectiveness. A similar argument has been made by Gubasta and Kaufman whose focus is institutional rather than national planning and policy. The authors present evidence that despite access to a highly developed computer-based system, information for institutional policy only became effective after it had been collected and shaped by hand in direct response to policy issues. The authors concluded their analysis as follows:

"If institutional leaders are to cope with the need for management information they must begin to influence the design and application of processes, tools and 
techniques employed by their institutions. . . Also, they must familiarize themselves with their institution's capabilities to generate information that meets these criteria. Without this thoughtful approach to the creation of information designed to aid decision makers in their planning, organizing, and controlling we predict management information systems will continue to produce few benefits at increasingly greater costs."*

\section{What should be done?}

It is time now to return to our starting point, to address the question of what information the policy makers need that they do not now have in regard to higher education. This is the same question which Sheffield took up and began to answer more than twenty years ago. Both the form and the substance of the answer today must be very different from his, not only because the levels of participation he articulated through his projections have in large measure been achieved (however short of perfection the achievement might be when translated into social or economic terms), but also because the change in scale of the enterprise combined with the public support and role of higher education has introduced a dimension of complexity unknown even two decades ago. To begin with, it is possible now to view participation rates as indicators which might fall as well as rise, instead of being driven relentlessly upward. If it is to be "capacity" rather than demography which sets levels of enrolment within the next decade, then participation will be influenced to fall and rise in a mirror image of the demographic "roller-coaster" while enrolment remains at a plateau. How fair would such variable participation be? We don't know how to answer this question; but we might observe that variable participation is no more arbitrary than pegging the rate at the most recent value, whatever that happens to be. Next, is such a plateau likely? Given that the metaphorical plateau might undulate like physical ones, both across the country and over time, we believe that during the next decade there will be an overriding concern in both universities and government-related agencies with maintaining the very considerable investment in human and physical capital which exists in the institutions. Nevertheless, so long as there is no rigid quota system for admissions (nor are we advocating one), a "plateau" projection can be more reliable than a "roller-coaster" one. There will, therefore, be an urgent need to monitor the complexities of student demand as it is affected both by general environmental factors and by direct policy interventions. An important indicator, we suggest, is the opportunity for part-time earnings. The evidence, sketchy as it is, indicates that opportunities are fewer now than they were two or three years ago and are likely to diminish in the near future. Another factor, the demand for specialized manpower, is notoriously unreliable; but publicity often serves more effectively in guiding choices than demand forecasts, and the publicity for most professions is uniformly pessimistic at this moment. The instruments of public policy are the supply of public funds for capital and the growth portion of recurrent support of universities along with funds for student aid and for creating students jobs. While some of these indicators might be available on a short-term basis within regions and

* J.L. Gubasta and N. Kaufman: reference 4, p. 411. This article was received while ours was in the final stages of preparation. The analysis and argument presented by the authors are in striking parallel to our own despite the differences in place, focus and background. The authors are at the University of Utah which was (and still is) among the strongest supporters of the WICHE and NCHEMS development of computer-based university information. 
provinces there is no locus yet for a national collection of such data. Similarly, information on the "capacity" of institutions should be brought together within regions and provinces (where this has not yet been done) and then exchanged nationwide, so that policies on inter-provincial mobility can be brought to bear on smoothing rather than exacerbating the effects of demographic shifts and changes. This is especially important given dramatic variations in the demographic roller coaster from one region to another in Canada.

\section{Who should do it?}

For all these purposes, there is needed a new device or an altered role for the AUCC as suggested in Chapter II, Planning for Planning (reference 7). Briefly, the suggestion put forward there was that the AUCC might take on the function of bringing together the regional and provincial collectivities in a national association and concurrently might work with Statistics Canada on developing the information (data plus analysis) needs of the collectivities. We have said emphatically that these needs are not now being met by the data collections instigated in Ontario, nor in what is being done by other government ministries. Their emphasis on accountability and their administrative requirement for detailed and precise data are understandable. In any case, these ministries are unlikely in the foreseeable future to relax their demands for control data. It makes sense, therefore, to consider a complementary role for national agencies, i.e. that of examining issues which cannot be dealt with by the Council of Ministers of Education or by them alone; it might be helpful here to think of the research wing of the Maritime Provinces Higher Education Commission as a forerunner, if not a model, of what might be possible.

To fulfill such a role, it will be necessary for Statistics Canada to think again about the purposes to be served by its data collection on higher education. To continue on the present course of amassing a comprehensive all-purpose system jointly with the provinces will be futile because the data will become increasingly remote from global policy issues, as we have already shown, as a result of increasing provincial intervention in the data base. To pursue the alternative of amalgamating the provincial collections will have a similar outcome accompanied by greater chaos as each province gears to meet its own funding arrangements. (We might note, for example, that all investigators have encountered much chaos when attempting to gather data on foreign students and faculty.) A more promising path would be the development of a national data collection which would have points of contact with the provincial collections but remain distinct from them. The national collection would be oriented toward Canada-wide policy and planning issues of concern to universities, provincial ministries and advisory boards, provincial collectivities of universities and the AUCC. It would have a common core of definitions negotiated with the provinces (some of which exist now), would follow procedures accommodated to those of the provinces (which is partly so now and will go to completion inevitably), but would abandon the disaggregated form and the irrelevant detail which now clutter the annual collection and would supplement it by well-chosen periodic surveys of the kind we have mentioned.

It should not be inferred from the foregoing that we advocate planning only at the national level. On the contrary, our complaint is that provincial data collection which gives priority to purposes of control at the provincial level while assuming the viability of 
the "all purpose" mode and of fully integrated provincial and national systems, substantially reduces the possibility of sound planning and policy development within provincial jurisdictions as well as nationally. To sum up, the data needs associated with control should be left entirely where they belong - in the provincial jurisdiction, while the resources of Statistics Canada and the energy of AUCC should be oriented in co-operation with the provinces to information associated with global, national and inter-provincial planning and policy questions.

\section{References}

1. Bill Ahamad, et al. Some Characteristics of Post-Secondary Students in Canada. Ottawa, Department of the Secretary of State, 1976.

2. Council of Ontario Universities. Foundation for an Uncertain Future: The Operating Base. Toronto, May 1977.

3. S. Dupré and N. Sisco. Report of the Interim Committee on Student Financial Assistance. Toronto, January 1977.

4. J.L. Gubasta and N. Kaufman. "Developing Information for Academic Management: an alternative to computer-based systems": Journal of Higher Education, XLVIII, July 1977.

5. O.E.C.D. Reviews of National Policies for Education: Canada. Paris, 1976.

6. Edward F. Sheffield. Enrolment in Canadian Universities and Colleges, 1961, 1963 and 1966 projections. Ottawa, AUCC.

7. Bernard Trotter and A.W.R. Carrothers. Planning for Planning. Ottawa, AUCC, 1974.

8. I. Waniewicz. The Demand for Part.Tiem Learning in Ontario. Toronto, O.I.S.E. and O.E.C.A., 1975.

9. Miles Wisenthal. "Enrolment Fluctuations and Patterns for the Future". A paper presented to AUCC Annual Conference, 1973. Ottawa, Statistics Canada.

10. Zoltan Zsigmond. "Impact of Projected Population Trends on Post-Secondary Education, 19612001 ". A paper presented to the Statistical Science Association of Canada at the Learned Societies, May 1975.

11. Z. Zsigmond, G. Picot, M.S. Devereaux and W. Clark. Future Trends in Enrolment and Manpower Supply in Ontario. 1977. Ottawa, Statistics Canada. 